\title{
The role of galectin-3 in the tumorigenesis and progression of pituitary tumors
}

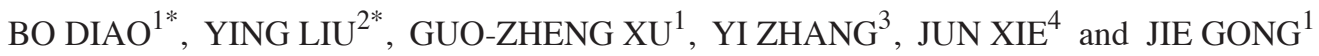 \\ ${ }^{1}$ Department of Neurosurgery, Wuhan General Hospital of Guangzhou Command and Hubei Key Laboratory of \\ Central Nervous System Tumor and Intervention; Departments of ${ }^{2}$ Clinical Laboratory, ${ }^{3}$ Clinical Experiment and \\ ${ }^{4}$ Science and Training, Wuhan General Hospital of Guangzhou Command, Wuhan, Hubei 430070, P.R. China
}

Received February 21, 2017; Accepted November 2, 2017

DOI: $10.3892 / \mathrm{ol} .2018 .7931$

\begin{abstract}
Galectin-3 (Gal-3), a $\beta$-galactoside-binding protein, has been implicated in cell proliferation, cell adhesion, and the progression and metastasis of various types of cancer. The present study investigated the involvement of Gal-3 in the tumorigenesis and progression of pituitary tumors using three rat pituitary tumor cell lines. Following transfection with Gal-3 expression and interference vectors, the impact of Gal-3 on proliferation, apoptosis and migration of pituitary tumor cells was been investigated. Meanwhile, BCL2 associated X, apoptosis regulator (Bax), caspase-3 and matrix metalloproteinase 7 (MMP7) protein expression levels were analyzed by western blotting. The results of the present study revealed that Gal-3 expression in $\mathrm{GH} 3$ and $\mathrm{GH} 4 \mathrm{C} 1$ cells was higher than in $\mathrm{RC}-4 \mathrm{~B} / \mathrm{C}$ cells. Furthermore, Gal-3 was demonstrated to promote the proliferation and migration of $\mathrm{GH} 3$ and $\mathrm{GH} 4 \mathrm{C} 1$ cells, and inhibit cell apoptosis. Caspase-3 and MMP7 protein expression was also increased by Gal-3, while Bax expression was decreased. These results suggested that Gal-3 serves an important function in the tumorigenesis and development of pituitary tumors, and it may be a useful target for the treatment of pituitary tumors in the future.
\end{abstract}

Correspondence to: Dr Jie Gong, Department of Neurosurgery, Wuhan General Hospital of Guangzhou Command and Hubei Key Laboratory of Central Nervous System Tumor and Intervention, 627 Wuluo Road, Wuhan, Hubei 430070, P.R. China

E-mail:mmmlife10@sina.com

Dr Jun Xie, Department of Science and Training, Wuhan General Hospital of Guangzhou Command, 627 Wuluo Road, Wuhan, Hubei 430070, P.R. China

E-mail: xjun1977@126.com

*Contributed equally

Key words: pituitary adenomas, galectin-3, proliferation, apoptosis, migration

\section{Introduction}

Pituitary adenomas are one of the most common intracranial tumors; having the third highest morbidity rate of all intracranial tumors following brain gliomas and meningiomas (1). Pituitary adenomas are divided into different classifications through tumor size and hormone secretion function (2). According to tumor size, pituitary adenomas are divided into microadenomas and macroadenomas by an arbitrary cutoff size of $10 \mathrm{~mm}$ (2). According to hormone secretion, the tumors are divided into hormone-secreting pituitary adenomas and nonfunctional adenomas (2). Although the majority of pituitary adenomas are benign and rarely progress to malignancies, they are usually aggressive due to hormone excessive or insufficiency (1). Due to the partial pressure of the tumor and disordered pituitary hormone secretion, pituitary adenomas are characterized by a series of clinical symptoms which seriously affect the quality of life of the patients. The aim of the present study was to identify objective molecular markers to predict the aggressive potential of tumors, and guide strategies for surgery and medical treatment.

In our previous study, gene arrays were used to screen for differentially expressed genes in aggressive pituitary adenomas and a series of upregulated genes, including galectin-3 (Gal-3) were identified, indicating that Gal-3 may be involved in the invasive development of pituitary adenomas $(3,4)$. Gal-3, a $\beta$-galactoside-binding protein, is one of the most frequently investigated members of the galectin family. Gal-3 is involved in normal biological processes including cell growth, differentiation and cell adhesion, but is also involved in the progression of a number of types of cancer, including pituitary, thyroid, colon and breast cancer (5-8). However, the mechanisms underlying the involvement of Gal-3 in the tumorigenesis and development of pituitary adenomas remain unknown. In the present study, Gal-3 expression was detected in three different rat pituitary tumor cell lines (GH3, GH4C1 and RC-4B/C). Expression and knockdown vectors of Gal-3 were utilized to investigate the involvement of Gal-3 in the tumorigenesis and progression of pituitary tumors, and provide a theoretical basis for treatment of pituitary tumors.

\section{Materials and methods}

Cell culture. Three kinds of rat pituitary tumor cell lines GH3 was obtained from BeNa Culture Collection (Kunshan, China), 
and $\mathrm{GH} 4 \mathrm{C} 1$ and $\mathrm{RC}-4 \mathrm{~B} / \mathrm{C}$ were obtained from American Type Culture Collection (ATCC; Manassas, VA, USA). Cells were maintained in Dulbecco's modified Eagle's medium (DMEM; Gibco, Thermo Fisher Scientific, Inc., Waltham, MA, USA) supplemented with $15 \%$ horse serum (Gibco, Thermo Fisher Scientific, Inc.), $2.5 \%$ fetal bovine serum (FBS; Gibco, Thermo Fisher Scientific, Inc.), $100 \mathrm{U} / \mathrm{ml}$ penicillin and $100 \mu \mathrm{g} / \mathrm{ml}$ streptomycin, and were maintained at $37^{\circ} \mathrm{C}$ in a $5 \%$ $\mathrm{CO}_{2}$ humidified environment.

Reverse transcription-quantitative polymerase chain reaction (RT-qPCR) analysis of Gal-3. Total cellular RNA was extracted from pituitary tumor cells using TRIzol reagent (Omega Bio-Tek, Inc., Norcross, GA, USA) according to the manufacturer's instructions. Then, RNA was reverse-transcribed into cDNA using PrimeScript ${ }^{\mathrm{TM}}$ RT reagent kit with gDNA Eraser, and cDNA amplification was performed using a SYBR Green PCR assay (both from Takara Bio, Inc., Dalian, Japan). The transcriptional levels of genes were calculated using the $2^{-\Delta \Delta C q}$ method (9). The PCR reaction (20 $\mu \mathrm{l}$ total volume) contained $10 \mu 12 \mathrm{X}$ SYBR Premix Ex Taq ${ }^{\mathrm{TM}}$ (Takara Bio, Inc., Otsu, Japan), $0.40 \mu \mathrm{mol} / 1$ each primer and $0.2 \pm 0.02 \mu \mathrm{g}$ cDNA template. The following three-step RT-qPCR reaction was performed: Pre-denaturation at $95^{\circ} \mathrm{C}$ for $30 \mathrm{sec}$, followed by 40 cycles of denaturation at $95^{\circ} \mathrm{C}$ for $5 \mathrm{sec}$, annealing at $56-60^{\circ} \mathrm{C}$ for $20 \mathrm{sec}$ and elongation at $72^{\circ} \mathrm{C}$ for $20 \mathrm{sec}$. The sequences for the primers are as follows: Gal-3 sense, 5'-CCCCGCTTCAATGAGA-3' and antisense, 5'-GAA TGGTTTGCCGCTC-3'; $\beta$-actin sense, 5'-CGTTGACATC CGTAAAGAC-3' and antisense, 5'-TAGGAGCCAGGGCAG TA-3'.

Construction of expression and interference vectors and cell transfection. The Gal-3 gene was amplified using primers (Gal-3 forward, 5'-ATAGGATCCATGGCAG ACGGCTTCTCACTT-3' and reverse, 5'-ATCGAAGAC TTAGATCATGGCGTGGGAAG-3') and was inserted into the corresponding site of the pGPU6/GFP/Neo vector (GenePharma Co., Ltd., Shanghai, China) according to the manufacturer's instructions to construct the overexpression vector pGPU6/GFP/Neo-Gal-3-Homo-1. Negative control pGPU6/GFP/Neo-shNC (target sequence, 5'-GTTCTCC GAACGTGTCACGT-3'), and Gal-3 interference vectors pGPU6/GFP/Neo-shGal-3-Homo-A (target sequence, 5'-AGC CTTCCCAGGGCAACCTGG-3') were purchased from GenePharma Co., Ltd. Cells were seeded in cell plates with DMEM and cultured until the cells reached $70-80 \%$ confluence, and then were transfected with $800 \mathrm{ng} /$ well expression plasmids or interference plasmids using Lipofectamine 2000 (Invitrogen; Thermo Fisher Scientific, Inc.) according to the manufacturer's instructions. The untransfected cells served as the control group.

MTT assay. Cell proliferation was measured using an MTT assay. GH3 and $\mathrm{GH} 4 \mathrm{C} 1$ cells were seeded in 96-well plates and transfected with interference vectors, expression vectors or empty control vectors. At the indicated time-points following transfection (24, 48 and $72 \mathrm{~h}$ ), $20 \mu \mathrm{l}$ MTT ( $5 \mathrm{mg} / \mathrm{ml}$; Bioswamp; Wuhan Beinglay Biological Technology Co., Wuhan, China) was added to each well. Following incubation for $4 \mathrm{~h}$, the medium was removed and $150 \mu \mathrm{l}$ DMSO was added to each well. Following shaking at low speed for $10 \mathrm{~min}$, the absorbance of converted the dye was measured at a wavelength of $490 \mathrm{~nm}$.

Cell apoptosis assay. Apoptosis analysis was performed using Annexin V-fluorescein isothiocyanate (FITC)/propidium iodide (PI) flow cytometry kit (BD Biosciences, Franklin Lakes, CA, USA) according to the manufacturer's instructions. GH3 and GH4C1 cells were transfected with Gal-3 interference vectors, empty vectors or expression vectors using Lipofectamine 2000. Cells were washed $48 \mathrm{~h}$ after this three times with ice-cold PBS and resuspended in $200 \mu \mathrm{l}$ of binding buffer at a concentration of $1 \times 10^{6}$ cells $/ \mathrm{ml}$. Annexin V-FITC $(10 \mu \mathrm{l})$ and PI $(10 \mu \mathrm{l})$ were added and cells were incubated for $30 \mathrm{~min}$ at $4^{\circ} \mathrm{C}$ in the dark. Finally, $300 \mu 1$ binding buffer was added and the cells were analyzed using flow cytometry (Cytomics FC 500) within $1 \mathrm{~h}$ and the results analyzed using CXP 2.1 Software (both from Beckman Coulter, Brea, CA, USA).

Cell migration assay. Cell migration and invasion were assessed by Transwell assays. GH3 and GH4C1 cells from different groups were starved with serum-free DMEM medium for $24 \mathrm{~h}$. Cells were diluted to $1 \times 10^{5}$ cells $/ \mathrm{ml}$ and $200 \mu 1$ cell suspension was added in the upper Transwell chambers (Corning Inc., Corning, NY, USA), and $500 \mu \mathrm{l}$ DMEM medium supplemented with 10\% FBS (Gibco; Thermo Fisher Scientific, Inc.) in the lower chambers, this was repeated three times for every group. Following incubation for $48 \mathrm{~h}$ in 24 -well plates at $37^{\circ} \mathrm{C}$, cells were fixed for $10 \mathrm{~min}$ using $1 \mathrm{ml} /$ well $4 \%$ paraformaldehyde (Bioswamp; Wuhan Beinglay Biological Technology Co.), stained by $0.5 \%$ crystal violet (Bioswamp; Wuhan Beinglay Biological Technology Co.) for $30 \mathrm{~min}$ at room temperature and washed 3 times using 1X PBS. Finally, the Transwell plates were wiped carefully with a cotton swab to remove non-migrated cells, and viewed under an optical microscope (Nikon Corporation, Tokyo, Japan) at magnification of $\mathrm{x} 200$ to count the number of cells.

Western blot analysis. Antibodies against Gal-3 (cat. no. ab2785; dilution 1:1,000), BCL2 associated X apoptosis regulator (Bax; cat. no. ab32503; dilution 1:2,000), caspase-3 (cat. no. ab90437; dilution 1:1,000), matrix metalloproteinase 7 (MMP7; cat. no. ab5706; dilution 1:1,000) and $\beta$-actin (cat. no. ab8227; dilution 1:2,000) were all purchased from Abcam (Cambridge, UK). Western blot analysis was performed as previously described (10). Briefly, cells were washed with PBS and lysed in lysis buffer $(20 \mathrm{mmol} / 1$ Tris-HCL pH 7.4, $150 \mathrm{mmol} / 1 \mathrm{NaCl}, 0.5 \%$ Nonidet P-40, $1 \mathrm{mmol} / 1$ EDTA, $50 \mu \mathrm{g} / \mathrm{ml}$ leupeptin, $30 \mu \mathrm{g} / \mathrm{ml}$ aprotinin, and $1 \mathrm{mmol} / \mathrm{l}$ PMSF). The protein concentration was determined by BCA kit (Bioswamp; Wuhan Beinglay Biological Technology Co.) Equal amounts of protein $(30 \mu \mathrm{g})$ were separated by $10 \%$ SDS-PAGE and then transferred onto PVDF membrane (EMD Millipore, Billerica, MA, USA). The membranes were blocked for $2 \mathrm{~h}$ at room temperature with $5 \%$ skim milk in TBS $(20 \mathrm{mmol} / \mathrm{l}$ Tris, $500 \mathrm{mmol} / 1 \mathrm{NaCl}$, and $0.05 \%$ Tween20). Subsequently, the membrane was incubated with primary 
A

B

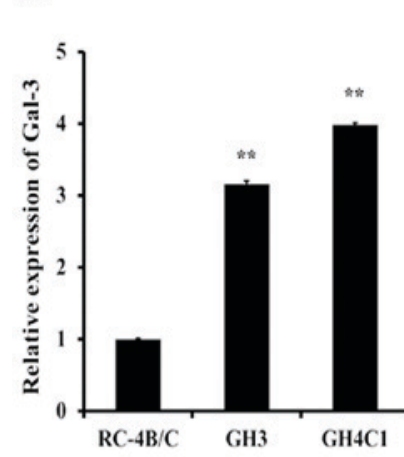

D

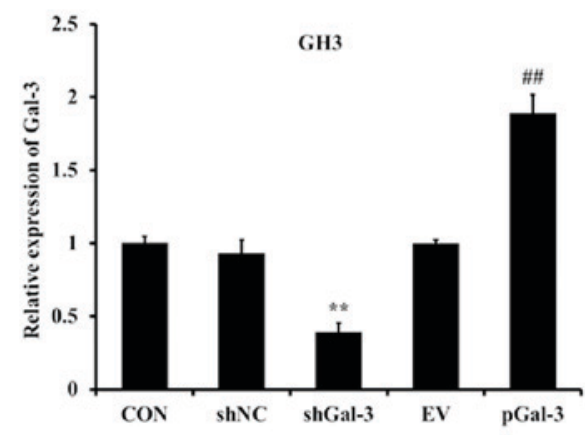

C

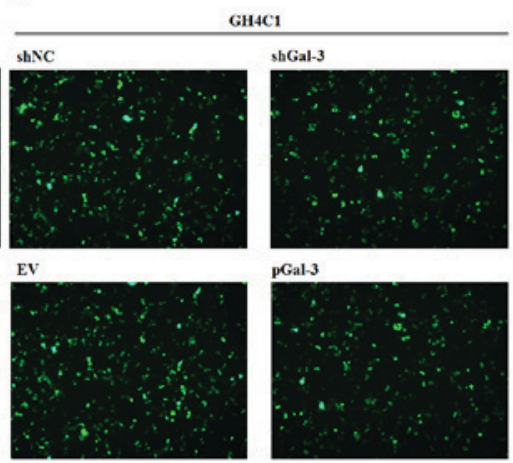

E

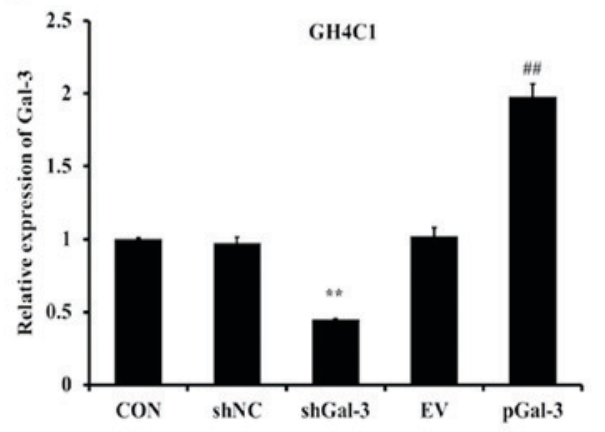

Figure 1. Expression of Gal-3 in rat pituitary tumor cell lines. (A) The mRNA levels of Gal-3 in three different cell lines (GH3, GH4C1 and RC-4B/C) were detected by RT-qPCR. (B) GH3 cells and (C) GH4C1 cells transfected with shNC, shGal-3, EV and pGal-3 and detected by fluorescence microscopy (magnification, x200). The mRNA expression levels of Gal-3 in (D) GH3 cells and (E) GH4C1 cells transfected with shNC, shGal-3, EV and pGal-3 ${ }^{* *} \mathrm{P}<0.01$ vs. RC-4B/C or shNC; ${ }^{\#} \mathrm{P}<0.01$ vs. shGal-3. Gal-3, galectin-3; shNC, negative control interference vector; shGal-3, galectin-3 interference vector; EV, empty vector control; pGal-3, galectin-3 overexpression vector; $\mathrm{CON}$, control.

antibodies overnight at $4^{\circ} \mathrm{C}$. Then, the membranes were washed twice with TBS and incubated in biotinylated goat anti-rabbit IgG secondary antibody (cat. no. W4011; 1:3,000 dilution; Promega Corporation, Madison, WI, USA) for $2 \mathrm{~h}$ at room temperature. Immunoreactivity was visualized by colorimetric reaction using ECL substrate buffer (EMD Millipore). Membranes were scanned with Gel Doz EZ imager (Bio-Rad Laboratories, Inc., Hercules, CA, USA).

Statistical analysis. Data were expressed as the mean \pm standard deviation. Data were analyzed by one-way analysis of variance using SPSS 19.0 software (IBM Corp, Armonk, NY, USA), followed by Dunnett's or Duncan's tests for multiple comparisons. $\mathrm{P}<0.05, \mathrm{P}<0.01$ and $\mathrm{P}<0.001$ were considered to indicate a statistically significant difference.

\section{Results}

Expression of Gal-3 in rat pituitary tumor cells. To explore the expression levels of Gal-3 in rat pituitary tumor cells, three cell lines were selected to undergo RT-qPCR, and the results revealed that Gal-3 expression levels were increased in $\mathrm{GH} 3$ and $\mathrm{GH} 4 \mathrm{C} 1$ cells compared with $\mathrm{RC}-4 \mathrm{~B} / \mathrm{C}$ cells (Fig. 1A). As presented in Fig. 1B and C, the interference vector (shGal-3) and expression vector (pGal-3) were successfully expressed in GH3 and GH4C1 cells. Then, the expression efficiency of the vectors was assessed with RT-qPCR, which revealed that shGal-3 significantly reduced
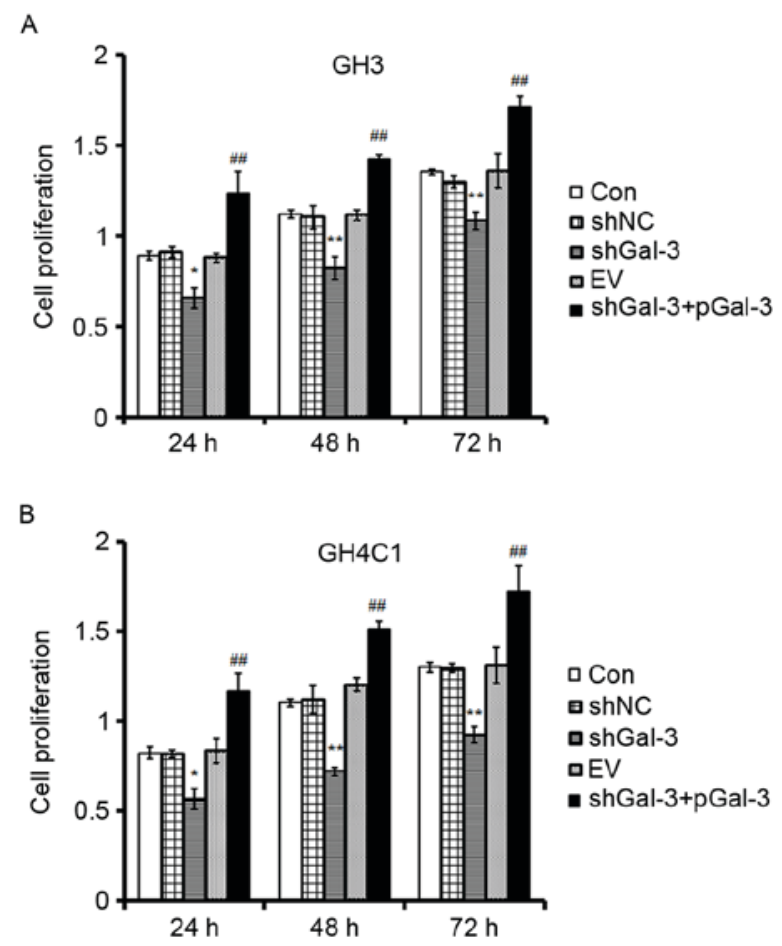

Figure 2. Gal-3 promoted $\mathrm{GH} 3$ and $\mathrm{GH} 4 \mathrm{C} 1$ cell proliferation, as assessed using MTT assays. (A) GH3 and (B) GH4C1 cell proliferation following transfection with shGal-3 was decreased compared with the shNC group, while the proliferation was increased in the shGal-3+pGal-3 group compared with the shGal-3 group. ${ }^{* *} \mathrm{P}<0.01$ vs. shNC; ${ }^{\# \#} \mathrm{P}<0.01$ vs. shGal-3. Gal-3, galectin-3; shNC, negative control interference vector; shGal-3, galectin-3 interference vector; EV, empty vector control; pGal-3, galectin-3 overexpression vector; $\mathrm{CON}$, control. 
A
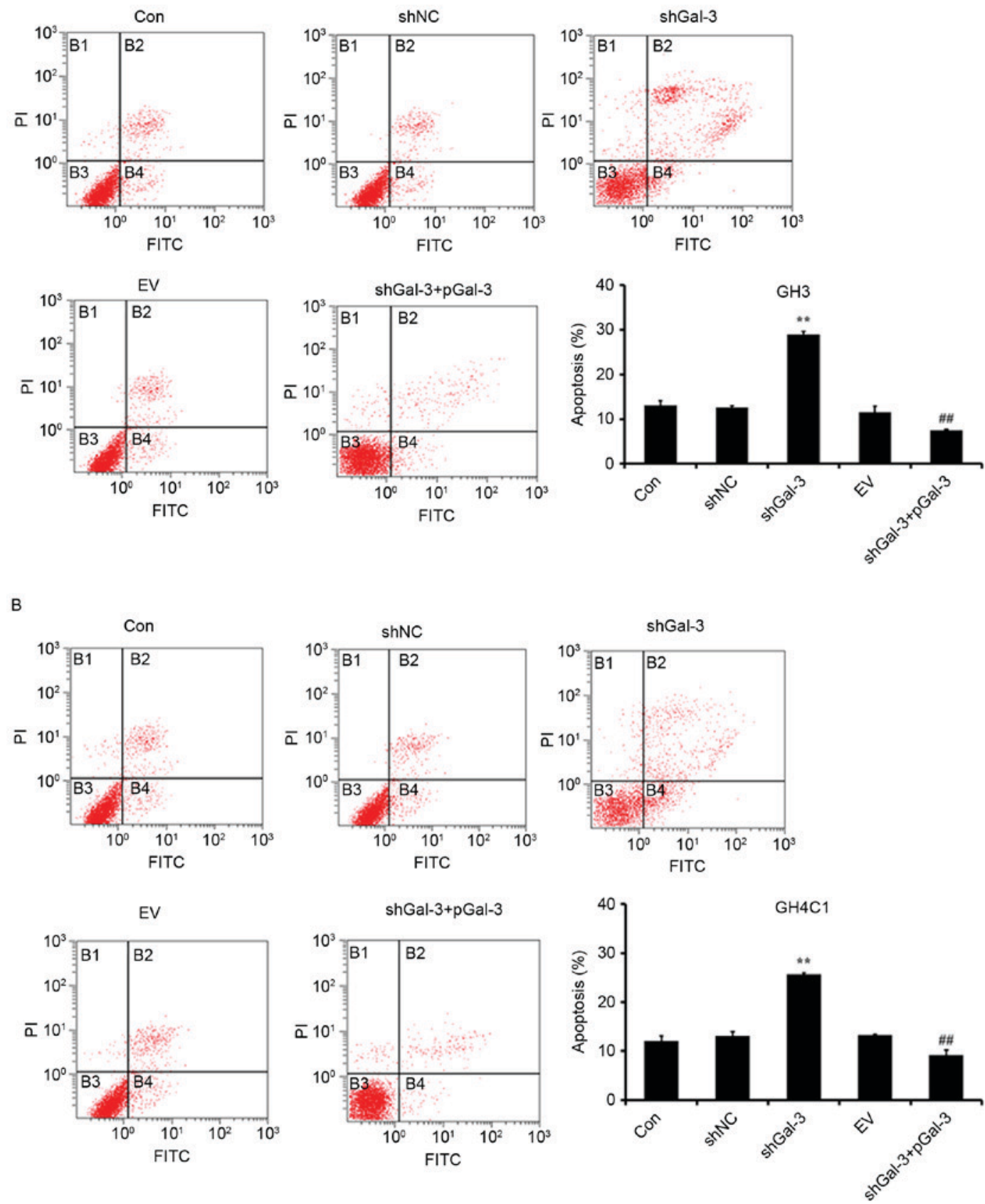

Figure 3. Gal-3 reduces apoptosis in rat pituitary tumor cell lines. Apoptosis in (A) GH3 and (B) GH4C1 cells was assessed using flow cytometry. ${ }^{* *} \mathrm{P}<0.01$ vs. shNC; ${ }^{\# / 4} \mathrm{P}<0.01$ vs. shGal-3. Gal-3, galectin-3; shNC, negative control interference vector; shGal-3, galectin-3 interference vector; $\mathrm{EV}$, empty vector control; pGal-3, galectin-3 overexpression vector; CON, control; FITC, fluorescein isothiocyanate; PI, propidium iodide.

the expression of Gal-3 and pGal-3 markedly increased the expression level of Gal-3 compared with their respective controls (Fig. 1D and E).

The effect of Gal-3 on rat pituitary tumor cell proliferation. Cell proliferation was measured by MTT. There were five groups: $\mathrm{CON}$ (control), shNC (cells transfected with the negative control interference vector), shGal-3 (cells transfected with shGal-3), EV (cells transfected with an empty vector) and shGal-3+pGal-3 (cells transfected with shGal-3 initially, and then the Gal-3 expression vector). As presented in Fig. 2, cell proliferation in the shGal-3 group was decreased compared with the shNC group at 24,48 and $72 \mathrm{~h}$. Cell proliferation in the shGal-3+pGal-3 group was also significantly increased in a time-dependent manner compared with the shGal-3 group (Fig. 2). The results indicated that Gal-3 promoted the proliferation of $\mathrm{GH} 3$ and $\mathrm{GH} 4 \mathrm{C} 1$ cells.

Effect of Gal-3 on rat pituitary tumor cell apoptosis. Cell apoptosis was measured by Annexin V-FITC/PI flow cytometry. As presented in Fig. 3, transfection with shGal-3 significantly increased the percentage of apoptotic cells compared with the shNC group, while the shGal-3+pGal-3 group had decreased apoptosis compared with the shGal-3 group. These results 
A
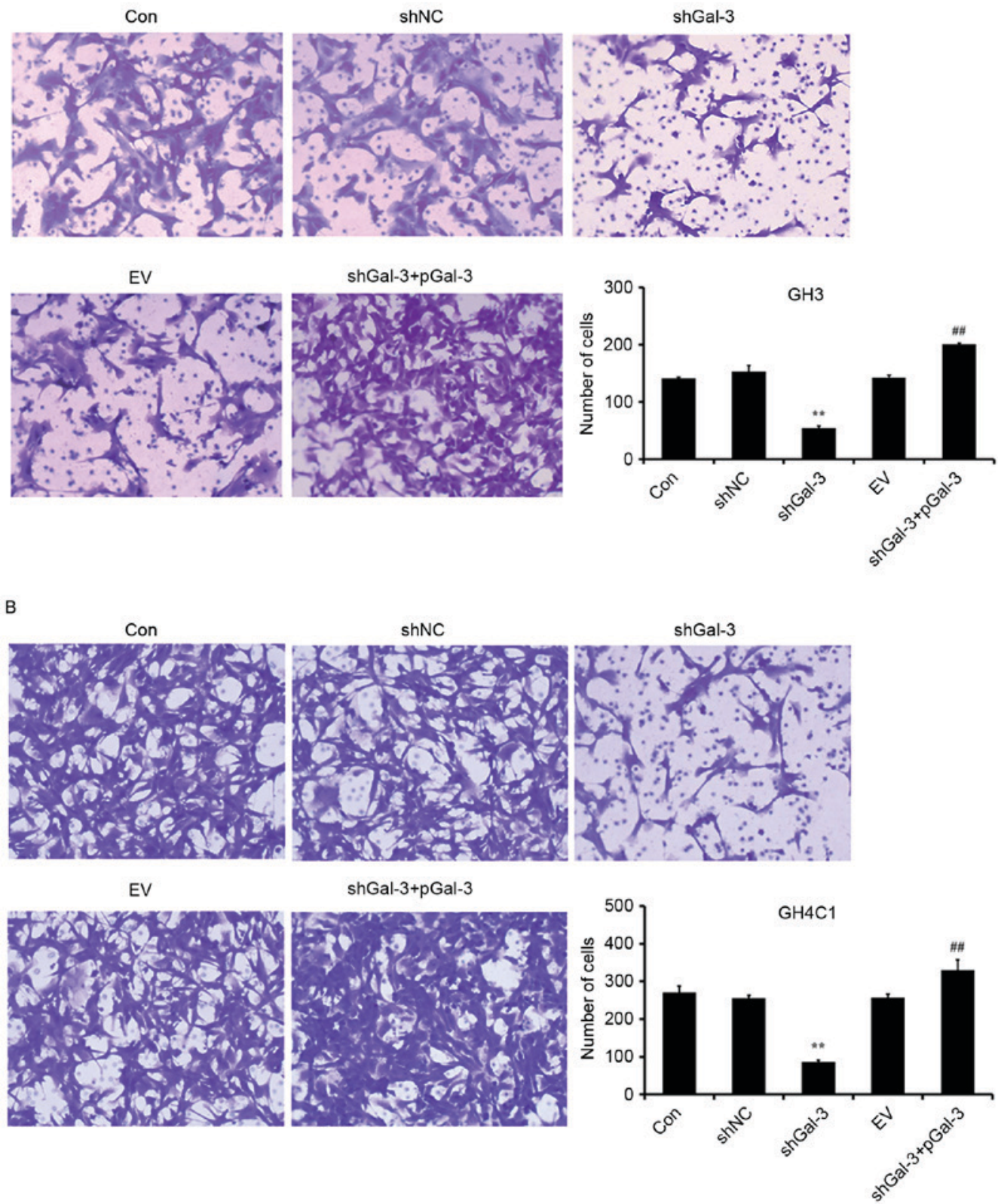

Figure 4. Gal-3 promoted the migration of rat pituitary tumor cell lines. Migration was assessed in (A) GH3 and (B) GH4C1 cells by Transwell assays (magnification, $\mathrm{x} 200)$. ${ }^{* *} \mathrm{P}<0.01$ vs. shNC; ${ }^{\# \#} \mathrm{P}<0.01$ vs. shGal-3. Gal-3, galectin-3; shNC, negative control interference vector; shGal-3, galectin-3 interference vector; $\mathrm{EV}$, empty vector control; pGal-3, galectin-3 overexpression vector; $\mathrm{CON}$, control.

indicated that Gal-3 inhibited the apoptosis of GH3 and GH4C1 cells.

Effect of Gal-3 on rat pituitary tumor cell migration. Cell migration was assessed using a Transwell test. As presented in Fig. 4, transfection with shGal-3 significantly decreased the number of migrating cells compared with the shNC group, while shGal-3+pGal-3 groups significantly increased the migration of cells compared with shGal-3. These results indicated that Gal-3 increased the migration of $\mathrm{GH} 3$ and $\mathrm{GH} 4 \mathrm{C} 1$ cells.

Effect of Gal-3 on apoptosis-associated genes and oncogenes. In order to further understand the effect of Gal-3 on apoptosis-associated genes and oncogenes, the expression of Bax, caspase-3 and MMP7 were detected by Western blot.
As presented in Fig. 5, in $\mathrm{GH} 3$ and $\mathrm{GH} 4 \mathrm{C} 1$ cells, the protein expression levels of caspase-3 and MMP7 were decreased while Bax expression was increased in the shGal-3 group compared with the controls. In addition, caspase-3 and MMP7 protein expression were increased following overexpression of Gal-3, while Bax expression was decreased (Fig. 5).

\section{Discussion}

Galectins are a family of animal lectins with diverse biological functions. They are involved in extracellular and intracellular processes: Extracellularly, by interacting with cell-surface and extracellular matrix glycoproteins and glycolipids, and intracellularly, by interacting with cytoplasmic and nuclear proteins to regulate signaling pathways (11). 

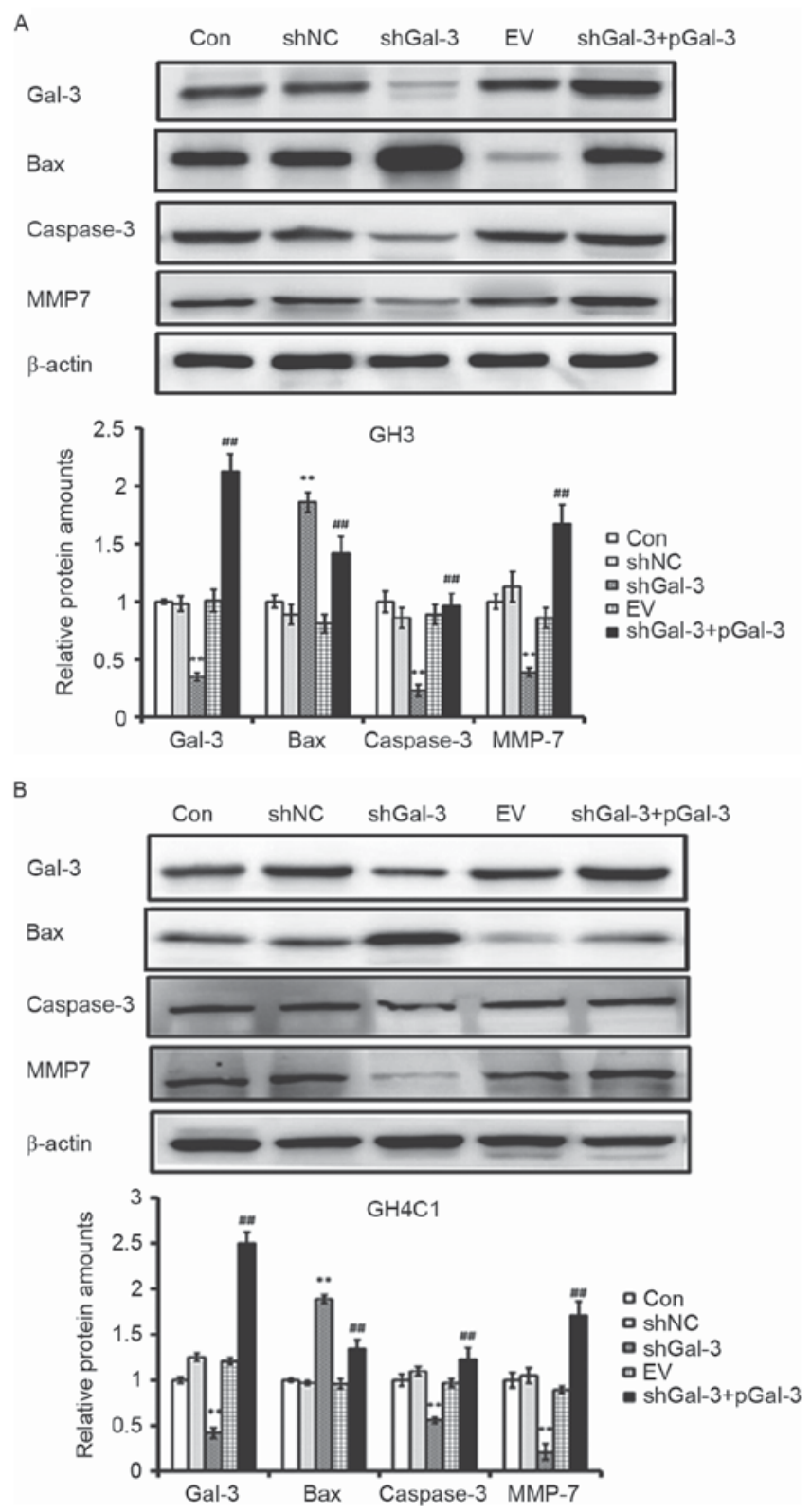

Figure 5. Effect of Gal-3 on the expression of apoptosis-associated genes and oncogenes. The expression of apoptosis-associated genes in (A) GH3 and (B) GH4C1 cells was detected by western blotting. Representative blots and the fold changes in each protein to $\beta$-actin ratio are presented. ${ }^{* *} \mathrm{P}<0.01$ vs. shNC; ${ }^{\# /} \mathrm{P}<0.01$ vs. shGal-3. Gal-3, galectin-3; shNC, negative control interference vector; shGal-3, galectin-3 interference vector; EV, empty vector control; pGal-3, galectin-3 overexpression vector; $\mathrm{CON}$, control; Bax, BCL2-associated X, apoptosis regulator; MMP7, matrix metalloproteinase 7.

Previous research has demonstrated that galectins serve vital functions in cancer and that they contribute to neoplastic transformation, the maintenance of transformed phenotypes, tumor cell adhesion and survival, angiogenesis and tumor metastasis (12). Among the different members of the galectin family, Gal-3 has been reported to be involved in various biological processes, including cell proliferation and differentiation, tumor cell adhesion, apoptosis, tumor progression and metastasis.

In the present study, Gal-3 expression levels in $\mathrm{GH} 3$ and GH4C1 cells were increased compared with RC-4B/C cells. Then, two pituitary tumor cell lines were selected for further study concerning the role of Gal-3 on cell proliferation, cell apoptosis, cell migration and the expression of apoptosis-associated genes and oncogenes. In a previous study, inhibition of Gal-3 gene expression by RNA interference decreased HP75 cell proliferation and increased apoptosis (13). The present study demonstrated that inhibition of Gal-3 expression following transfection with RNA interference vectors decreased cell proliferation, migration and the expression of caspase-3 and MMP7 in $\mathrm{GH} 3$ and $\mathrm{GH} 4 \mathrm{C} 1$ cells, but increased cell apoptosis and expression of the apoptosis-associated gene Bax. Furthermore, following interference with Gal-3 expression, overexpression of Gal-3 repaired the reduction of cell proliferation, migration and expression of caspase- 3 and MMP7, and inhibited cell apoptosis and Bax protein expression. These results indicated that Gal-3 contributes to the tumorigenesis and progression of pituitary tumors.

Gal-3 is expressed in a number of types of tumor, and the intensity of its expression and localization depend on tumor progression, invasiveness and metastatic potential (14). Previous evidence suggests that Gal-3 may be a useful biomarker for differential diagnosis of brain tumors, including various glioneuronal tumors, pituitary adenomas, meningiomas and schwannomas (15). The present study is focused on the involvement of Gal-3 on pituitary adenomas. Given the function of Gal-3 in pituitary tumor cell proliferation and apoptosis, Gal-3 may be a potential target for the treatment of aggressive pituitary tumors. However, the precise mechanisms by which Gal-3 promotes the tumorigenesis and progression of pituitary tumors require further study.

\section{Acknowledgements}

The present study was supported by grants from Project of Health and Family Planning Commission of Hubei Province (grant nos. WJ2015MA012 and WJ2015MB118).

\section{References}

1. Jiang $X$ and Zhang $X$ : The molecular pathogenesis of pituitary adenomas: An update. Endocrinol Metab (Seoul) 28: 245-254, 2013.

2. Chatzellis E, Alexandraki KI, Androulakis II and Kaltsas G: Aggressive pituitary tumors. Neuroendocrinology 101: 87-104, 2015.

3. Gong J, Diao BO, Yao GJ, Liu Y and Xu GZ: Analysis of regulatory networks constructed based on gene coexpression in pituitary adenoma. J Genet 92: 489-497, 2013.

4. Huang CX, Hou YH and Liu YS: Expression of galectin-3 correlates with apoptosis in pituitary adenoma cells. Neurosci Bull 24: 34-38, 2008.

5. Arfaoui-Toumi A, Kria-Ben Mahmoud L, Ben Hmida M, Khalfallah MT, Regaya-Mzabi S and Bouraoui S: Implication of the galectin-3 in colorectal cancer development (about 325 tunisian patients). Bull Cancer 97: E1-E8, 2010.

6. Manivannan P, Siddaraju N, Jatiya L and Verma SK: Role of pro-angiogenic marker galectin-3 in follicular neoplasms of thyroid. Indian J Biochem Biophys 49: 392-394, 2012.

7. Yamaki S, Fujii T, Yajima R, Hirakata T, Yamaguchi S, Fujisawa T, Tsutsumi S, Asao T, Yanagita Y, Iijima M and Kuwano H: Clinicopathological significance of decreased galectin-3 expression and the long-term prognosis in patients with breast cancer. Surg Today 43: 901-905, 2013.

8. Huang CX, Zhao JN, Zou WH, Li JJ, Wang PC, Liu CH and Wang YB: Reduction of galectin-3 expression reduces pituitary tumor cell progression. Genet Mol Res 13: 6892-6898, 2014.

9. Livak KJ and Schmittgen TD: Analysis of relative gene expression data using real-time quantitative PCR and the 2(-Delta Delta C(T)) method. Methods 25: 402-408, 2001. 
10. Na YJ, Jeon YJ, Suh JH, Kang JS, Yang KH and Kim HM Suppression of IL-8 gene expression by radicicol is mediated through the inhibition of ERK1/2 and p38 signaling and negative regulation of NF-kappaB and AP-1. Int Immunopharmacol 1: 1877-1887, 2001

11. Liu FT and Rabinovich GA: Galectins as modulators of tumour progression. Nat Rev Cancer 5: 29-41, 2005.

12. Newlaczyl AU and Yu LG: Galectin-3-a jack-of-all-trades in cancer. Cancer Lett 313: 123-128, 2011.

13. Riss D, Jin L, Qian X, Bayliss J, Scheithauer BW, Young WF Jr, Vidal S, Kovacs K, Raz A and Lloyd RV: Differential expression of galectin-3 in pituitary tumors. Cancer Res 63: 2251-2255, 2003.
14. Righi A, Jin L, Zhang S, Stilling G, Scheithauer BW, Kovacs K and Lloyd RV: Identification and consequences of galectin-3 expression in pituitary tumors. Mol Cell Endocrinol 326: 8-14, 2010.

15. Park SH, Min HS, Kim B, Myung J and Paek SH: Galectin-3: A useful biomarker for differential diagnosis of brain tumors. Neuropathology 28: 497-506, 2008.

cc) (i) $($ This work is licensed under a Creative Commons cc) Attribution-NonCommercial-NoDerivatives 4.0 International (CC BY-NC-ND 4.0) License. 